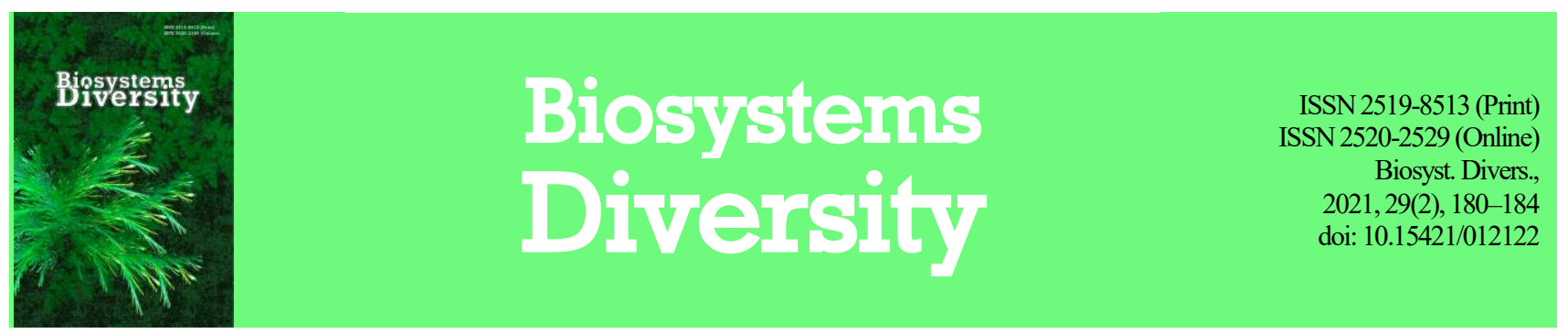

\title{
The biology of Simulium noelleri and Simulium dolini: morphological, ecological and molecular data
}

\author{
M. O. Zinchenko, K. B. Sukhomlin, O. P. Zinchenko, V. S. Tepliuk \\ Lesya Ukrainka Volyn National University, Lutsk, Ukraine
}

Article info

Received 14.04.2021

Received in revised form

17.05.2021

Accepted 18.05.2021

Lesya Ukrainka

Volyn National

University, 13 Voli av,

Lutsk, 43025, Ukraine

Tel.: $+38-0332-720-123$

E-mail:

Sukhomlin.Katerina@

vпu.edu.ua

\section{Zinchenko, M. O., Sukhomlin, K. B., Zinchenko, O. P., \& Tepliuk, V. S. (2021). The biology of Simulium noelleri and Simulium dolini: morphological, ecological and molecular data. Biosystems Diversity, 29(2), 180-184. doi:10.15421/012122}

\begin{abstract}
Molecular genetic research has revolutionized the taxonomy and systematics of the Simuliidae family. Simulium noelleri Friederichs, 1920 is a species of blackfly, common in the Holarctic, reported for 33 countries. In 1954, Topchiev recorded it in Ukraine for the first time. Simulium dolini Usova et Sukhomlin, 1989 has been recorded at the borders of Ukraine and Belarus. It was described for the first time by Usova and Sukhomlin in 1989 from the collection from the territory of Volyn region in 1985. Usova and Sukhomlin, Yankovsky, Adler state that $S$. noelleri and $S$. dolini are different species by the morphological characteristics that differ in all phases of development. Adults differ in the structure of the genital appendages, palps, the margin and shape of the face and forehead, the colour of the legs; the larva - in the pattern on the frontal capsule, the number of rays in the fans, mandibular teeth and the hypostoma, the structure of the hind organ of attachment; pupae - in the branching way of gills. Molecular data are becoming an increasingly important tool in insect taxonomy. Therefore, we had to check that these two closely related species also have genetic difference. The development of S. noelleri and S. dolini was studied in four small rivers of Volyn region, Ukraine (Chornohuzka, Konopelka, Putylivka, Omelyanivka) in the period from 2017 to 2019. During initial processing of insect samples, we used the standard protocols EPPO PM7/129. We obtained the nucleotide sequence of $S$. dolini. It was proved that the populations of $S$. noelleri and $S$. dolini from medium and small rivers of Volyn differ in biological, morphological, behavioural and genetic characteristics. Comparison of the species $S$. noelleri with the data of the GenBank confirms the identification of three distinct morphotypes from Volyn, Great Britain and Canada. As a result of the conducted researches, it was confirmed that two close species of $S$. dolini and S. noelleri from the noelleri species group differ in the structure of mitochondrial DNA, which confirms their independent taxonomic status. Additional studies comprising more individuals from larger areas of Europe are required to verify the taxonomic position of these two species.
\end{abstract}

Keywords: blackflies; noelleri species group; Ukraine; mitochondrial DNA; mitochondrial cytochrome c oxidase subunit I (COI); taxonomy; genetic differences.

\section{Introduction}

Simulium noelleri Friederichs, 1920 is a species of blackfly, common in the Holarctic, reported for 33 countries (Adler, 2020. World black flies (Diptera: Simuliidae): A comprehensive revision of the taxonomic and geographical inventory). In 1954, Topchiev recorded the species in Ukraine for the first time. Simulium dolini Usova et Sukhomlin, 1989 was recorded within Ukraine and Belarus. The species was first described by Usova and Sukhomlin (1989) from the 1985 collection from the territory of the Volyn region, Lutsk district, Polonka village, and the Chomohuzka River. Both species belong to the noelleri group. Overall, three species of this group have been recorded in Ukraine: $S$. noelleri, $S$. dolini and $S$. palustre Rubtsov, 1956. The habitats of larvae and pupae of the noelleri species group are medium (Turia) and small (Chernyavka, Lyutka, Vyzhivka, Konopelka, Teklya, Pliska, Kezyuvka, Serebryanitsya, Kalynivka, Rudka, Tsir, Cherevaha, Serna) rivers, streams, reclamation canals and hydraulic locks. They mostly inhabit stones and aquatic vegetation. These species are recorded as active bloodsuckers of farm animals and humans (Sukhomlin \& Zinchenko, 2007). According to Usova \& Sukhomlin (1989), Yankovsky (2002), Adler (2020), S. noelleri and S. dolini are different species by morphological characteristics, differing in all phases of the development. Adults differ in the structure of the genital appendages, palps, the margin and shape of the face and forehead, the colour of the legs; the larva - in the mandibular teeth and hypostoma, the pattern on the forehead, the shape and size of the postgenal cleft; pupae - in the branching way of the gills. Molecular data are becoming an increasingly important tool in insect taxonomy (Simon et al., 1994; Sebastiani et al., 2001; Szalanski et al., 2006).
In Europe, similar studies have been conducted by Lithuanian scientists (Bernotiene \& Stunzenas, 2009) for S. reptans (Linnaeus, 1758) and $S$. galeratum Edwards, 1920. Studies of COI gene sequences have shown that all the specimens collected in Lithuania belonged to $S$. galeratum. The species status of $S$. galeratum blackflies was confirmed in the United Kingdom (Day et al., 2008) using molecular taxonomy, based on the strict correlation between the molecular variation and the morphotypes. S. reptans and closely related species (S. galeratum and S. reptantoides Carlsson, 1962) from Central and Northern Europe were characterized based on genetic variability, haplotype number and haplotype distribution (Kudela et al., 2004).

Taxonomic status of the Prosimulium italicum Rivosecchi blackfly (Diptera: Simuliidae) based on genetic evidence was studied by Slovak scientists (Kúdela et al., 2018).

Chromosomal mutations were studied in species of the genus Simulium (Adler et al., 2016). An extreme example of nonrandom rearrangements, especially inversion breaks, was described in the polytene chromosome of the $S$. bergi Rubtsov, 1956 blackfly from Armenia and Turkey.

For the group of noelleri species, such studies have not been carried out, which determined the relevance of our work. In the literature, there is only information about lectotype designation for S. noelleri (Zwick, 1986), features of larvae behaviour in a water column (Wotton, 2008). Also, there were studies of the cytogenetics of the Holarctic blackfly $S$. noelleri (Adler $\&$ Kachvorian, 2001). Analyses were made for polytene chromosomes of S. noelleri from 16 areas in Armenia, Canada, England, Germany, Russia, and Sweden. The biology and morphology of noelleri species group in the European mixed forest zone was described (Kaplich et al., 2015; Sukhomlin et al., 2019). 
Therefore, we had to check that these two closely related species also have genetic difference. Comparison of our data about the structure of mitochondrial DNA of the two species with each other and with the data of the GenBank will help solve the question of the status of these species of blackfly, which are of great economic importance for Ukraine.

\section{Material and methods}

In the period 2017-2019, the development of S. noelleri and S. dolini was studied in four small rivers of Volyn region, Ukraine (Chornohuzka, Konopelka, Putylivka, Omelyanivka). The material was collected from April to November at least twice a month.

The research was carried out in the Konopelka river (Sokyrychi village 50 51'51"N 2529'55"E), the Chomohuzka River (Polonka village $\left.50^{\circ} 68^{\prime} 41^{\prime \prime N} 25^{\circ} 29^{\prime} 96^{\prime \prime E}\right)$, r. Putylivka $\left(50^{\circ} 82^{\prime} 77^{\prime \prime N} 25^{\circ} 88 ' 37^{\prime \prime} \mathrm{E}\right)$, and the Omelyansvka River (city of Lutsk 5074'86"N25⒉'06"E).

The larvae and pupae of Simuliidae were collected from the aquatic vegetation (Glyceria maxima (Hartman) Holmb., 1919 or Butomus umbellatus L., 1753). The larvae of blackflies were counted and measured in the laboratory using a microscope (MBS-10).

In Fig. 1 and 2, there are used the following abbreviations: $a$ - antenna, $a s$ - anal sclerite, $c$ - cocoon, $f$ - fans, $f a$ - frontoclypeal apotoma, $g$ gill, $h$ - hypopharynx, $h s$ - hypostoma, $h s c$ - hooks, spine comb of the pupal abdomen, $h s t$ - hypostomal teeth, in - intertorma, $m d$ - mandible, $m p-$ maxillary palpus, $m t$ - mandibular teeth, $m x$ - maxilla, $p c l-$ postgenal cleft.

The material for the study of the genetic structure was collected in 2019. Larvae and pupae were stored in $96 \%$ ethanol at $-20^{\circ} \mathrm{C}$ for further analysis.

During the initial processing of insect samples, we used recommended EPPO PM7/129 Standard (EPPO, 2016). Briefly, total DNA from individual larvae and pupa of different species was extracted, using the DNeasy Blood \& Tissue Kit (Qiagen, Hilden, Germany) according to the manufacturer's instructions for Animal Tissue. PCR-settings to amplify of the mitochondrial cytochrome $\mathrm{c}$ oxidase subunit I (COI) gene of insects was adapted from Folmer et al. (1994) using the primer combination LCO1490: 5'-GGT CAA CAA ATC ATA AAG ATA TTG G-3' and HCO2198: 5'-TAA ACT TCA GGG TGA CCA AAA AAT CA-3'. PCR Mastermix using $20 \mathrm{mg} / \mathrm{Ml}$ BSA was prepared according to the EPPO Standard. PCR amplification was performed using the proposed PCR program with an initial denaturation at $95^{\circ} \mathrm{C}$ for $2 \mathrm{~min}$, followed by denaturation at $95^{\circ} \mathrm{C}$ for $30 \mathrm{~s}$, annealing at $49^{\circ} \mathrm{C}$ for $30 \mathrm{~s}$, and extension at $72{ }^{\circ} \mathrm{C}$ for $1 \mathrm{~min}$, followed by $72{ }^{\circ} \mathrm{C}$ for $10 \mathrm{~min}$, with a final $120 \mathrm{~min}$ extension step at $8^{\circ} \mathrm{C}$. To check for successful DNA amplification, the PCR products were separated on $1 \%$ agarose gel.

The presence or absence of the PCR product was determined using a sample on agarose gel stained with GelRed. Amplified DNA fragments were sequenced in both directions by Sanger's method using the ExoStar kit for sequencing reactions following the manufacturer's protocol. Sequence configuration was performed by comparing free DNA strands. Editing of DNA sequences, configurations of assembly and alignment of consensus sequences, phylogenetic analysis were performed using the version X of MEGA software (Kumar et al., 2018).

Standard software packages of Statistic10 (StstSoft Inc., USA) for PC were used for statistical data analysis. The data are given as mean value with standard error $(x \pm S E)$.

\section{Results}

Biology research S. dolini and S. noelleri. Simulium dolini is lownumbered and uncommon species. Larvae and pupae are found in small rivers, reclamation canals. They inhabit mainly aquatic vegetation that grows on gullies and rapids of water bodies, where the flow velocity can reach $0.7 \mathrm{~m} / \mathrm{s}$, the content of dissolved oxygen in water is $55-82 \%$, it develops at the water temperature of $+4 \ldots+18^{\circ} \mathrm{C}$. The maximum density of larvae, measuring 200 individuals $/ \mathrm{dm}^{2}$, was recorded on April 15, 2018 in the the Konopelka River in Sokyrychi village. It has one generation per year, flight occurs in the third decade of May. It winters in the egg phase.
It is a bloodsucker of humans and domestic animals (Sukhomlin et al, 2019). Blood sucking activity takes place from late May to mid-June.

Places of detection in Ukraine are: Turia, Konopelka, Chernyavka, Vyzhivka rivers, streams in the territory of the Shatsk National Nature Park (Volyn region), Stubla, Vyrka, Veselukha (Rivne region), Zherev, Struchok, Osliv, Loznytsia (Zhytomyr region), a network of reclamation canals.

Simulium noelleri is an abundant and broadly distributed species. Habitats of larvae and pupae are small rivers, reclamation canals and hydraulic locks. They mostly inhabit stones, aquatic vegetation. The species develops in the water temperature of $+6 \ldots+22{ }^{\circ} \mathrm{C}$, prefers areas of water bodies with gullies, where the flow velocity is up to $0.9 \mathrm{~m} / \mathrm{s}$, the content of dissolved oxygen in water is $51-77 \%$. The maximum density of immature phases (500 individuals/ $\mathrm{dm}^{2}$, recorded on April 21, 2018 in the Konopelka River, Sokyrychi village) was observed in the second decade of May. There may develop 3-4 generations, flight of which is not manifested clearly: the departure of the first generation takes place in May, the second - in late June, the third - in early August, the fourth - in early September. It winters in the egg or larva phase. It is a bloodsucker of humans and domestic animals (Sukhomlin et al., 2019). Attacks on animals and humans are observed from May to the end of June.

Places of detection in Ukraine are: Rivers Lyutka, Vyzhivka, Konopelka, Teklya, Plyska, Kezyuvka, Serebryanytsia, Kalynivka, Rudka, Tsyr, Cherevakha, Serna, streams on the territory of the Shatsk National Nature Park (Volyn region), Yazvynka, Stubla, Rudynka, Zamchysko, Vyrka (Rivne region), Bobrivka, Ubort, Irsha, Loznitsa, Teteriv, Uzh (Zhytomyr region), stream (Kyiv region), Desna, Ubed, Vyunitsa, Trubizh, Borzenka, Mena, Zamglay, Krista, Golovesnya, stream (Chernihiv region), reclamation canals near hydraulic locks.

Study of S. dolini and S. noelleri morphology. Larva S. dolini. Body length 7.7-7.8 mm (Fig. 1), color grey, dark head.

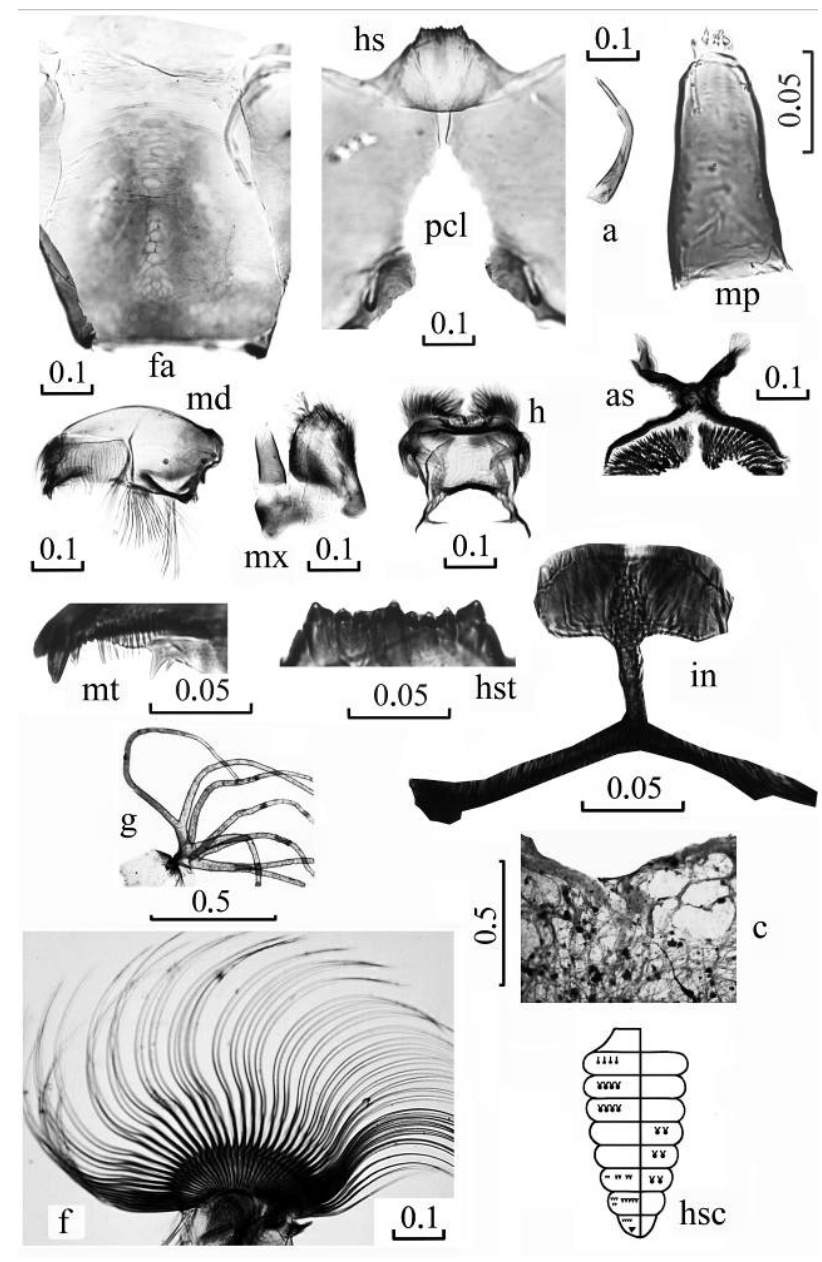

Fig. 1. Immature phases of Simulium dolini Usova et Sukhomlin: a list of abbreviations is given in the materials and methods; scale bar in $\mathrm{mm}$ 
Head. The pattern on the forehead is H-shaped, small, poorly manifested, most obscured in the middle and at the base. The antenna is short $(0.30 \mathrm{~mm})$, the $1 \mathrm{st}$ segment $(0.07 \mathrm{~mm})$ is twice as short as the $2 \mathrm{nd}$ and 1.5 times shorter than the 3rd. There are 39-48 rays in a large fan. The mandible (length $0.34 \mathrm{~mm}$, width $0.15 \mathrm{~mm}$ ) is rounded at the upper margin; apical tooth is wedge-shaped, short; anterior pre-apical tooth is twice longer than the middle and posterior; has 9 internal teeth; sharp marginal teeth, posterior is very small and closely adjacent to the anterior. The maxillary palpus is small $(0.13 \mathrm{~mm}$ length, $0.06 \mathrm{~mm}$ width). The hypostoma is elongated, trapezoidal, $0.16 \mathrm{~mm}$ long, twice greater than its width $(0.08 \mathrm{~mm})$; bears $3-4$ bristles on the sides. The middle tooth of the hypostoma is located above the level of the lateral teeth. The postgenal cleft is narrow, sharp arch-like ( $0.30 \mathrm{~mm}$ long, $0.10 \mathrm{~mm}$ wide), the length is more than half of the buccal scleritis.

Abdomen. Chitinous frame with thin branches, the upper $(0.10 \mathrm{~mm})$ are smaller than lower ones $(0.16 \mathrm{~mm})$, reaching the 11th row of hooks. In the posterior organ of attachment, there are 60-70 rows of hooks, with 11-13 hooks in each.

Pupa of S. dolini. Body length is $3.0-4.1 \mathrm{~mm}$. Abdominal tergites VII-IX have irregular rows of small spines. The caudal spines are very small. There are 8 gills, located in pairs in different planes $(2+2+2+2)$. The upper gill extends upward and bends at approximately a right angle. The lower gill is on a longer stem. The upper and lower gills form angle of $150^{\circ}$. The cocoon is flabby with an openwork anterior margin.

Larva of S. noelleri. Body length is $7.8-8.5 \mathrm{~mm}$ (Fig. 2), dark grey, the head is light brown.

Head. The pattern on the forehead is small, poorly manifested, $\mathrm{H}$ shaped, the lower branches are better expressed than the upper ones, the places of muscle attachment are lightly coloured. The antenna is short $(0.26 \mathrm{~mm})$; the 1 st segment $(0.06 \mathrm{~mm})$ is twice as short as the $2 \mathrm{nd}$ and 1.5 times shorter than the 3rd segment. There are 48-52 rays in a large fan. The mandible is rectangular, elongated, its length $(0.32 \mathrm{~mm})$ is two times its width $(0.15 \mathrm{~mm})$. The apical tooth is thin, long (larger than the outer), its length to the anterior pre-apical one is $0.005 \mathrm{~mm}$; anterior preapical tooth large (length $0.15 \mathrm{~mm}$ ), three times longer and two times wider than the middle and posterior apical teeth, which are equal to each other; there are 11 internal teeth, they are long and arranged in one row; marginal teeth are located closely, the front one is much larger than the posterior. Maxilla has a well-developed maxillary palpus (length $0.14 \mathrm{~mm}$, width $0.04 \mathrm{~mm}$ ). The hypostoma is slightly elongated, $0.15 \mathrm{~mm}$ long, two greater than the width $(0.065 \mathrm{~mm})$, bears 4 bristles on the sides. The middle tooth of the hypostoma is located above the level of the lateral teeth; intermediate teeth gradually decrease from external to internal. The postgenal cleft of the head capsule is sharp arch-like, deep $(0.24 \mathrm{~mm}), 0.12 \mathrm{~mm}$ wide, it almost reaches the hypostoma.

Abdomen. The chitinous frame is thin. The upper branches $(0.13 \mathrm{~mm})$ are smaller than the lower ones $(0.16 \mathrm{~mm})$, reaching the 11th row of hooks. The posterior organ of attachment bears 66-74 rows of hooks, with 10-13 hooks in each.

Pupa S. noelleri. Body length is $3.0-3.5 \mathrm{~mm}$. Abdominal tergites VII and VIII have one row of spines of various sizes. Tergite IX with bears small spines and caudal spines. The cocoon is openwork, flabby. There are 8 gills, located in different planes (formula $2+1+1+2+2$ ). The bottom pair of filaments is located on the swollen stalk. The upper and lower threads form an angle of about $125^{\circ}$.

Nucleotide sequence change of the COI gene in S. dolini and S. noelleri. Collected samples of 685-bp COI gene fragment were sequenced from two individuals of $S$. dolini and two individuals of $S$. noelleri and compared with three samples of $S$. noelleri (GenBank FJ524745.1, KP861066.1, KP861067.1 from Canada and the United Kingdom). The COI sequences from the $S$. noelleri showed an $\mathrm{A}+\mathrm{T}$ bias in nucleotide content $($ mean $=63.7 \%$ ) relative to the $\mathrm{C}+\mathrm{G}$ content $($ mean $=36.3 \%)$, as is typical of arthropods (Crease, 1999; EPPO, 2016). The individual average percentage of nucleotide content was: $\mathrm{A}=27.0 \%, \mathrm{~T}=36.7 \%, \mathrm{C}=$ $19.5 \%, \mathrm{G}=16.8 \%$. The content of thymine in samples from Volyn was higher than in samples from Canada and lower than in samples from Great Britain, the content of adenine was higher than in samples from $\mathrm{Ca}$ nada and Britain. Simulium dolini samples differ from all studied S. noelleri samples by higher content of adenine.
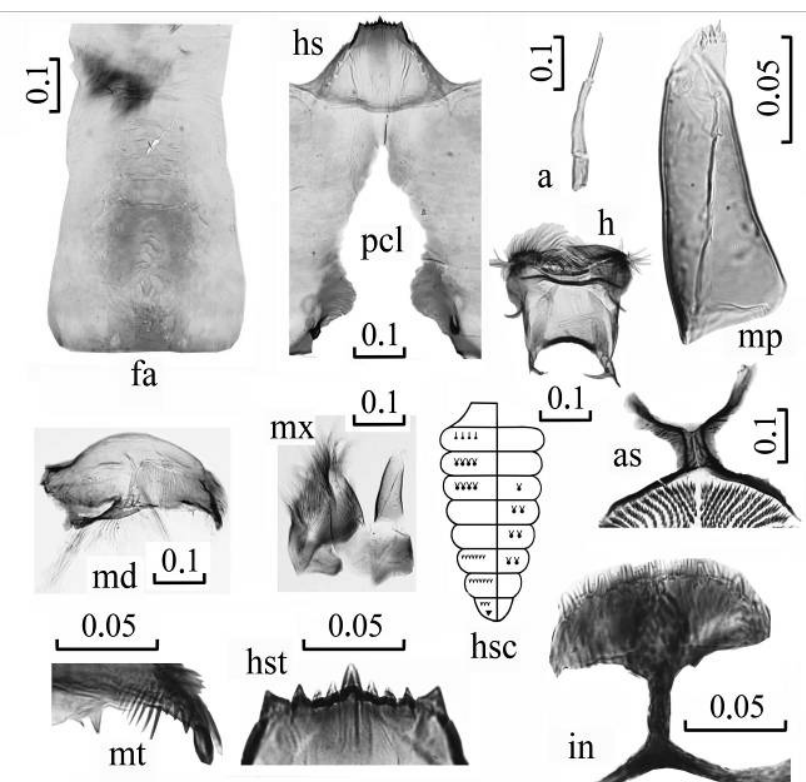

0.1


Fig. 2. Immature phases of Simulium noelleri Friederich: a list of abbreviations is given in the materials and methods; scale bar in $\mathrm{mm}$

Table 1

Nucleotide frequencies in the studied samples and GenBank data

\begin{tabular}{lcccc}
\hline \multicolumn{1}{c}{ Species } & $\mathrm{T}(\mathrm{U}), \%$ & $\mathrm{C}, \%$ & $\mathrm{~A}, \%$ & $\mathrm{G}, \%$ \\
\hline S.dolini 1 & 37.0 & 20.3 & 26.4 & 16.3 \\
S.dolini 1 & 36.6 & 19.4 & 27.4 & 16.6 \\
S.dolini 2 & 36.0 & 20.0 & 27.5 & 16.5 \\
S.dolini 2 & 36.6 & 19.4 & 27.0 & 17.0 \\
Avg. & 36.6 & 19.8 & 27.1 & 16.6 \\
S.noelleri 1 & 36.7 & 20.1 & 26.7 & 16.5 \\
S.noelleri 1 & 36.6 & 19.5 & 27.2 & 16.7 \\
S.noelleri 2 & 37.2 & 20.4 & 26.0 & 16.4 \\
S.noelleri 2 & 36.5 & 19.4 & 27.6 & 16.6 \\
Avg. & 36.8 & 19.9 & 26.9 & 16.6 \\
S. noelleri Canada & 36.6 & 19.9 & 26.6 & 16.9 \\
S. noelleri Brit 1 & 37.0 & 19.7 & 26.2 & 17.1 \\
S. noelleri Brit 2 & 37.0 & 19.5 & 26.7 & 16.8 \\
\hline
\end{tabular}

Note: nucleotides - A - adenine, $\mathrm{G}$ - guanine, $\mathrm{C}$ - cytosine, $\mathrm{T}$ - thymine, $\mathrm{U}$ - uracil; 1,2 - numbers of individuals, Brit-Britain.

Our nucleotide sequence of $S$. dolini:

TTTATTGAACTTCCCTTAGAATACTTATTCGAGCTGAATTAG GTCATCCCGGTTCCCTTATTGGAGATGATCAAATTTATAAT GTAATTGTTACAGCCCATGCTTTTGTAATAATTTTTTTCATA GTAATACCAATTATAATCGGAGGATTTGGAAATTGATTAGT GCCCCTAATATTAGGAGCCCCTGATATGGCCTTTCCCCGAA TAAACAATATAAGTTTCTGAATACTTCCCCCTTCCCTTACTC TTCTATTAGCCAGTAGTATGGTAGAAGCAGGAGCCGGGAC AGGTTGAACTGTCTATCCTCCCCTATCTTCTGGAATTGCTCA TGCGGGGGCTTCAGTTGATCTAGCAATTTTCTCCCTTCACTT AGCCGGAATTTCCTCTATTTTAGGAGCTGTAAATTTTATTAC AACCATTATTAATATACGATCTAATGGAATTACTTTTGATC GAATACCTTTATTTGTATGATCAGTTGTTATTACAGCTGTAT TACTTCTTTTATCTCTTCCTGTATTAGCTGGAGCTATCACAA TACTTTTAACAGATCGAAATCTAAATACATCATTTTTCGATC CTGCTGGAGGGGGAGACCCTATTCTTTACCAACA 


\section{Discussion}

The biology of S. dolini and S. noelleri is quite similar, as they are early spring species that live in small rivers, reclamation canals. They mainly inhabit aquatic vegetation that grows on gullies and rapids of water bodies, where the flow velocity can reach $0.7-0.9 \mathrm{~m} / \mathrm{s}$, the dissolved oxygen content in water equals $51-82 \%$, development occurs at water temperature of $+4 \ldots+22^{\circ} \mathrm{C}$ (Sukhomlin \& Zinchenko, 2007).

There is a difference in the number of generations and phases of wintering. S. dolini has one generation per year and flight in the third decade of May. It winters in the egg phase (Usova \& Sukhomlin, 1989). S. noelleri has 3-4 generations, the development of which overlap with one another and the flight is manifested unclearly: the first generation flies in May, the second - in late June, the third - in early August, the fourth - in early September. It winters in the egg or larva phase (Kaplich et al., 2015).

The comparison of morphological traits of $S$. noelleri of the Volyn population with the description given by Rubtsov (1956) confirmed that the specimens of larvae and pupae which we studied practically do not differ from this description. The comparison of morphological traits of $S$. noelleri of the Volyn population with the data of Davies (1966) revealed a slight difference in the number of rays in the larva fan. Individuals of the Volyn population have more rays $(50 \pm 2$, in the British population $48 \pm 2$ ), fewer internal mandibular teeth and rows in the larval organ of attachment. In the pupa phase, the difference is observed in the formula of the gills branching: in Volyn individuals and in Rubtsov's description formula is $2+1+1+2+2$, in the British $-3+1+2+2$ and in the angle of divergence of the filaments $-125^{\circ}$ and $135^{\circ}$, respectively.

Comparison of $S$. dolini morphological traits with different populations of $S$. noelleri confirmed clear morphological differences in 12 traits.

Traits and their characteristics.

1. Pattern on the frontal capsule: 0 - positive (dark on light background), distinct; 1 - positive, H-shaped large, clearly distinct (S. dolini); 2 - positive, H-shaped small, poorly manifested (S. noelleri).

2. The number of rays in the premandibular fans: $0-44 \pm 10$ (S. morsitans) (Rubtsov, 1956); 1 - the number of rays in the fan is $43 \pm 4$ (S. dolini) (Usova \& Sukhomlin, 1989); 2 - the number of rays in the fan is $50 \pm 2$ (S. noelleri) (Kaplich et al., 2015).

3 . The size of the hypostomal teeth: 0 - small; 1 - small strongly covered with scales $(S$. dolini); 2 - small loosely covered with scales (S. noelleri).

4. The middle tooth of the hypostoma: 0 - below the level of the lateral teeth (S. morsitans); 1 - above the level of lateral teeth (noelleri sp.g.).

5. The size of the apical mandibular tooth: 0 - small, dull; 1 - wedgeshaped, short (S. dolini); 2-thin, long, larger than the outer (S. noelleri).

6. Preapical teeth of the mandible: 0 - teeth decrease from anterior towards posterior; 1 - anterior preapical tooth two times longer than the middle and posterior ones (S. dolini); 2 - large anterior preapical tooth, three times longer and two times wider than the middle and posterior preapical teeth (S. noelleri).

7. Preapical mandibular spines: $0-6 \pm 1 ; 1-9 \pm 1$ (S. dolini); $2-$ $11 \pm 1$ (S. noelleri).

8. Mandibular teeth of the marginal plate: 0 - close to one another, anterior one is three times larger than the posterior one ( $S$. morsitans, $S$. dolini); 1 - anterior tooth is two times larger than the posterior one (S. noelleri).

9. Posterior circlet: 0 - rows of hooks $64 \pm 6$ (S. morsitans, S. dolini); 1 -rows of hooks $72 \pm 5$ (S. noelleri).

\section{Pupa.}

10. Branching of pupal gills filaments: 0 - in the same plane (S. morsitans); 1 - in different planes (noelleri sp.g.) (Yankovsky, 2002).

11. The formula of the gills branching: $0-8$ branching in pairs $(2+$ $2+2+2)(S$. morsitans, $S$. dolini $) ; 1-8(2+1+1+2+2)(S . n o e l l e r i) ; 2$ $-8(3+1+2+2)(S$. noelleri Britain) (Davies, 1968).

12. The angle between the upper and lower gills of the pupa: $0-$ about $180^{\circ} ; 1-150^{\circ}$ (S. dolini); $2-125-135^{\circ}$ (S. noelleri).

The evolutionary history was inferred by using the Maximum Likelihood method and General Time Reversible model (Nei et al., 2000). The tree with the highest log likelihood (-913.28) is shown. Initial tree(s) for the heuristic search were obtained automatically by applying Neighbor-Join and BioNJ algorithms to a matrix of pairwise distances estimated using the Maximum Composite Likelihood (MCL) approach, and then selecting the topology with superior log likelihood value. The proportion of sites where at least one unambiguous base is present in at least one sequence for each descendent clade is shown next to each internal node in the tree. This analysis involved 7 nucleotide sequences. There were a total of 657 positions in the final dataset. Evolutionary analyses were conducted in MEGA X (Tamura et al., 2007; Kumar et al., 2018).

The evolutionary history was researched using the Maximum Likelihood method and General Time Reversible model (Nei et al., 2000). The tree with the highest log likelihood (-913.28) is shown. Initial tree(s) for the heuristic search were obtained automatically by applying Neighbor-Join and BioNJ algorithms to a matrix of pairwise distances estimated using the Maximum Composite Likelihood (MCL) approach, and then selecting the topology with superior log likelihood value. The proportion of sites where at least one unambiguous base was present in at least one sequence for each descendent clade is shown next to each internal node in the tree. This analysis involved 7 nucleotide sequences. There were 657 positions in the final dataset. Evolutionary analyses were conducted in MEGA X (Tamura et al., 2007; Kumar et al., 2018).

The comparison of noelleri species group from Volyn and data from the GenBank (Rivera \& Currie, 2009; Day, J. J., \& Post, R. J. (2015) A question of attribution: The utility of DNA barcoding for resolving taxonomic imperatives within the British blackfly fauna (Diptera: Simuliidae). NCBI GenBank: Simulium noelleri voucher SnoeSuff-008 cytochrome oxidase subunit I (COI) gene, partial cds; mitochondrial. Retrieved from www.ncbi.nlm.nih.gov/nuccore/KP861067.1; www.ncbi.nlm.nih.gov/nuccore/KP861066.1) from Canada and the United Kingdom of the mitochondrial cytochrome c oxidase subunit I (COI) gene is presented in Figure 3. A clear separation of two clades of S. dolini and $S$. noelleri is visible. Isolation of $S$. dolini clade was confirmed by budstrep in 86\%. Three clear groups (morphotypes) from Volhynia, Great Britain and Canada were formed in the $S$. noelleri cluster. Thus, DNA barcoding confirmed the designation of $S$. dolini as a separate species.

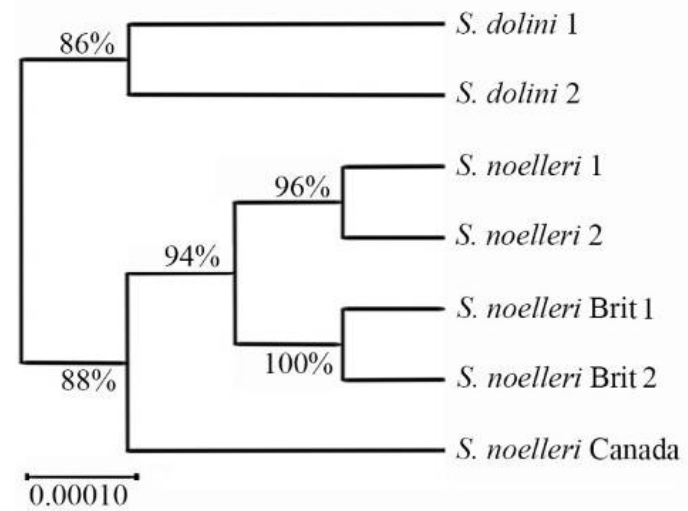

Fig. 3. Phylogenetic relationships of COI haplotypes (Maximum Likelihood method and General Time Reversible model): bootstrap values $(>50 \%)$ are shown above the branches of clades; S. noelleri Brit 1, S. noelleri Brit 2 (GenBank KP861066.1, KP861067.1), S. noelleri Canada (GenBank FJ524745.1) (Rivera \& Currie, 2009)

\section{Conclusions}

The COI barcoding gene correctly distinguished nearly $100 \%$ of our two species, thus demonstrating its utility to discriminate among morphologically similar blackfly species. Barcoding also revealed high levels of genetic divergence in lineages of sibling species, suggesting that it might prove useful for distinguishing cryptic diversity. In fact, populations of $S$. noelleri and $S$. dolini from the medium and small rivers of Volyn were found to be distinct among themselves (as previously suggested by morphology, behaviour, natural history, etc. evidence). Nonetheless, additional molecular techniques together with $\mathrm{COI}$ and perhaps other markers may 
be necessary to overcome difficulties associated with discriminating recently diverged sibling species.

The conducted researches confirm that two close species of $S$. dolini and $S$. noelleri from the $S$. noelleri species group differ in the structure of mitochondrial DNA, which confirms their independent taxonomic status.

The authors express their sincere gratitude to V. Gusarov, a leading researcher at the University of Oslo, for the opportunity to take part in the Ukrainian-Norwegian project on DNA barcoding of insects; V. O. Korneev, Head of Entomology and Collection Management Department, I. I. Schmalhausen Institute of Zoology, DSc, PhD, Full Professor, Corresponding Member of NAS of Ukraine; M. O. Kaliuzhna PhD, junior researcher, Department of Entomophages Systematics and Ecological Fundamentals of Biomethod, I. I. Schmalhausen Institute of Zoology NAS of Ukraine; G. V. Popov, PhD, senior researcher, Department of Entomology and Collection Management, I. I. Schmalhausen Institute NAS of Ukraine; O. B. Martinov PhD, senior researcher Department of Zoology, the National Museum of Natural History, NAS of Ukraine for assistance in organizing training at the Natural History Museum, University of Oslo.

The research is partially funded by project entitled "Training the new generation of entomologists in DNA-based molecular methods - international network (EntoMol)", supported by the Eurasia Programme 2017-2019 of the Norwegian Centre for International Cooperation in Education (SIU) (Project CPEA-LT- 2016/10140).

\section{References}

Adler, P. H., \& Kachvorian, E. A. (2001). Cytogenetics of the Holarctic black fly Simulium noelleri (Diptera: Simuliidae). Canadian Journal of Zoology, 79(11), 1972-1979.

Adler, P. H., Yildirim, A., Onder, Z., Tasci, G. T., Duzlu, O., Arslan, M. O., Ciloglu, A., Sari, B., Parmaksizoglu, N., \& Inci, A. (2016). Rearrangement hotspots in the sex chromosome of the Palearctic black fly Simulium bergi (Diptera, Simuliidae). Comparative Cytogenetics, 10(2), 295-310.

Bernotiene, R., \& Stunžènas, V. (2009). On the biology of Simulium galeratum in Lithuania: Ecological and molecular data. Ekologija, 55(2), 123-126.

Crease, T. J. (1999). The complete sequence for the mitochondrial genome of Daphnia pulex (Cladocera: Crustacea). Gene, 233, 89-99.

Davies, L. (1966). The taxonomy of British black-flies (Diptera: Simuliidae). Transactions of the Royal Entomological Society of London, 118(14), 413-506.

Day, J. C., Goodalls, T. I., \& Post, R. J. (2008). Confirmation of the species status of the blackfly Simulium galeratum in Britain using molecular taxonomy. Medical and Veterinary Entomology, 22, 55-61.

EPPO (2016). PM 7/129 (1) DNA barcoding as an identification tool for a number of regulated pests. EPPO Bulletin, 46, 501-537.

Folmer, O., Black, M., Hoeh, W., Lutz, R., \& Vrijenhoek, R. (1994). DNA primers for amplification of mitochondrial cytochrome $\mathrm{c}$ oxidase subunit I from diverse metazoan invertebrates. Molecular Marine Biology and Biotechnology, 3(5), 294-299.

Kaplich, V. M., Sukhomlin, E. B., \& Zinchenko, A. P. (2015). Moshki (Diptera: Simuliidae) smeshannyh lesov Evropy [Black-flies (Diptera: Simuliidae) of European mixed forests]. Novoe Znanie, Minsk (in Rassian).

Kúdela, M., Adler, P. H., \& Kúdelová, T. (2018). Taxonomic status of the black fly Prosimulium italicum Rivosecchi (Diptera: Simuliidae) based on genetic evidence. Zootaxa, 4377, 280-290.

Kudela, M., Bruderova, T., Jedlička, L., Bernotiene, R., Celec, P., \& Szemes, T. (2004). The identity and genetic characterization of Simulium reptans (Diptera: Simuliidae) from Central and Northem Europe. Zootaxa, 3802(3), 301-317.
Kumar, S., Stecher, G., Li, M., Knyaz, C., \& Tamura, K. (2018). MEGA X: Molecular evolutionary genetics analysis across computing platforms. Molecular Biology and Evolution, 35, 1547-1549.

Nei, M., \& Kumar, S. (2000). Molecular evolution and phylogenetics. Oxford University Press, New York.

Rivera, J. M., \& Currie, D. C. (2009). Identification of Nearctic black flies using DNA barcodes (Diptera: Simuliidae). Molecular Ecology Resources, 9(1), 224-236.

Rubtsov, I. A. (1956). Moshki (sem. Simuliidae). Fauna SSSR. Dvukrylye [Black-flies (family Simuliidae). Fauna of the USSR. Diptera]. Academy of Sciences of the USSR, Moscow - Leningrad (in Rassian).

Ruiz-Arrondo, I., Hernández-Triana, L. M., Ignjatović-Ćupina, A., Nikolova, N., Garza-Hernández, J. A., Rodríguez-Pérez, M. A., Oteo, J. A., Fook, A. R., \& Curdi, J. L. (2018). DNA barcoding of blackflies (Diptera: Simuliidae) as a tool for species identification and detection of hidden diversity in the eastem regions of Spain. Parasites and Vectors, 11, 463.

Sebastiani, F., Meiswinkel, R., Gomulski, L. M., Guglielmino, C. R., Mellor, P. S., Malacrida, A. R., \& Gasperi, G. (2001). Molecular differentiation of the Old World Culicoides imicola species complex (Diptera, Ceratopogonidae), inferred using random amplified polymorphic DNA markers. Molecular Ecology, 10, $1773-1786$.

Simon, C., Frati, F., Beckenbach, A., Crespi, B., Liu, H., \& Flook, P. (1994). Evolution, weighting, and phylogenetic utility of mitochondrial gene sequences and a compilation of conserved PCR primers. Annals of the Entomological Society of America, 87, 1-51.

Sukhomlin, E., Zinovieva, O., \& Kaplich, V. (2019). O patogennyh vidah moshek (Diptera, Simuliidae) podzony smeshannyh lesov Vostochnoj Evropy [About pathogenic species of black flies (Diptera, Simuliidae) of the Eastern Europe mixed forest subzone]. Scientific Bulletin of the Lesya Ukrainka East European National University, Biological Sciences, 387, 81-90 (in Rassian).

Sukhomlin, K. B., \& Zinchenko, O. P. (2007). Moshky (Diptera: Simuliidae) Volynskoho Polissia [Black flies (Diptera: Simuliidae) of Volin Polissya]. Vezha, Lutsk (in Ukranian).

Szalanski, A. I., Owens, C. B., Lewter, J. A., \& Broce, A. B. (2006). Genetic structure of Aedes vexans (Diptera: Culicidae) populations from Central United States based on mitochondrial ND5 sequences. Annals of the Entomological Society of America, 99(1), 157-163.

Tamura, K., Dudley, J., Nei, M., \& Kumar, S. (2007). MEGA4: Molecular evolutionary genetics analysis (MEGA) software version 4.0. Molecular Biology and Evolution, 24(8), 1596-1599.

Topchiev, A. G. (1954). Krovososushhie moshki jugo-vostoka USSR i mery bor'by $\mathrm{s}$ nimi [Blood-sucking black flies of the southeast of the Ukrainian SSR and measures to combat them]. In: Abstracts of reports of the III ecological conference. Kiev, 1, 263-265 (in Rassian).

Usova, Z. V., \& Sukhomlin, E. B. (1989). Novyj vid moshki-Simulium (Argentisimulium) dolini sp. n. (Diptera, Simuliidae) [A new species of black fly - Simulium (Argentisimulium) dolini sp. n. (Diptera, Simuliidae)]. Parasitology, 23(5), 423-427 (in Rassian).

Wotton, R. S. (1986). The use of silk life-lines by larvae of Simulium noelleri (Diptera). Aquatic Insects, 8(4), 255-261.

Yankovsky, A. V. (2002). Opredelitel' moshek (Diptera, Simuliidae) Rossii i sopredel'nyh territorij (byvshego SSSR) [Key to black flies (Diptera, Simuliidae) of Russia and adjacent territories (the former USSR)]. Zoological Institute of the Russian Academy of Sciences, Saint Petersburg (in Rassian).

Zwick, H. (1986). Lectotype designation for Simulium noelleri friederichs, 1920 (Diptera: Simuliidae). Aquatic Insects, 8(3), 140. 